\title{
PEMBERIAN PUPUK ORGANIK SEBAGAI CAMPURAN MEDIA TUMBUH BABY KAILAN (Brassica oleracea L.) SECARA VERTIKULTUR
}

\author{
The Addition of Organic Fertilizer as Mixed Growing Medium of Baby Kailan \\ (Brassica oleracea L.) Viticultural Planting
}

\author{
Sri Yoseva ${ }^{1}$, Sheibila Naqi Alfadillah ${ }^{2}$, Murniati $^{1}$ \\ ${ }^{1)}$ Dosen Jurusan Agroteknologi, Fakultas Pertanian, Universitas Riau \\ ${ }^{2)}$ Mahasiswa Jurusan Agroteknologi, Fakultas Pertanian, Universitas Riau \\ Email: bilanaqi180996@gmail.com \\ [Diterima: Agustus 2021; Disetujui: Desember 2021]
}

\begin{abstract}
The research aims to determine the effect of the addition of some organic fertilizers as a mixed growing medium for growth and yield of baby kailan and to get the best type of organic fertilizer to support the growth and yield of baby kailan plants in viticulture. The research was carried out at the the Experimental farm of the Agriculture Faculty, Riau University. The research took time four months, starting from February to May 2019 and the experiment, which consisted of four treatments and arranged using a completely randomized block design (RBD) of organic fertilizer, consisted of Cow manure, Goat manure, Chicken manure, and Oil Palm Empty Fruit Bunches (OPEFB) compost. The observed parameters were plant height $(\mathrm{cm})$, number of leaves (strands), fresh weight per plant (g), plant weight for consumption per plant $(\mathrm{g})$, and root volume $(\mathrm{ml})$. The observational data were analysed using the Statistical Analysis System (SAS) program. The results showed that the OPEFB compost treatment provided the best for the growth and yield of baby kailan. OPEFB compost gave the best results for all parameters.
\end{abstract}

Keywords: Verticulture, Baby Kailan, Organic Fertilizer

\begin{abstract}
Penelitian ini bertujuan untuk mengetahui pengaruh pemberian beberapa pupuk organik sebagai campuran medium tumbuh terhadap pertumbuhan dan hasil baby kailan secara vertikultur. Penelitian telah dilaksanakan di Kebun Percobaan Fakultas Pertanian Universitas Riau Kampus Bina Widya KM 12,5 Kelurahan Simpang Baru, Kecamatan Bina Widya, Pekanbaru. Penelitian berlangsung selama empat bulan mulai dari bulan Februari sampai Mei 2019. Penelitian dilaksanakan secara eksperimen yang terdiri dari empat perlakuan dan disusun menggunakan rancangan acak kelompok (RAK) dengan perlakuan yakni jenis pupuk organik yang terdiri dari: Pupuk kandang sapi, Pupuk kandang kambing, Pupuk kandang ayam, dan Kompos TKKS. Parameter yang diamati adalah tinggi tanaman $(\mathrm{cm})$, jumlah daun (helai), berat segar per tanaman $(\mathrm{g})$, berat tanaman layak konsumsi per tanaman $(\mathrm{g})$, dan volume akar $(\mathrm{ml})$. Data pengamatan yang diperoleh dianalisis menggunakan program Statistical Analysis System (SAS). Hasil penelitian menunjukkan bahwa perlakuan kompos TKKS memberikan pertumbuhan dan hasil tanaman baby kailan yang terbaik. Pemberian kompos TKKS memberikan hasil terbaik untuk semua parameter.
\end{abstract}

Kata kunci: Vertikultur, Baby Kailan, Pupuk Organik

\section{PENDAHULUAN}

Kailan (Brassica oleraceae, kelompok Alboglabra) merupakan sayuran yang masih satu spesies dengan kol atau kubis (Brassica oleracea, kelompok Capitata) (Pracaya, 2005). Kailan lebih diminati jika dipanen saat masih muda atau disebut dengan baby kailan
(Samadi, 2013). Kailan umumnya dipanen ketika sudah berumur 50-60 hari setelah pindah tanam (Hendra dan Andoko, 2014). Kebutuhan kailan dalam skala rumah tangga dapat dipenuhi dengan memanfaatkan pekarangan rumah secara optimal dengan melakukan budidaya menggunakan polybag yang disusun berdasarkan sistem vertikultur. 
Sanusi dan Benny (2010) menyatakan bahwa budidaya sistem vertikultur memiliki beberapa kelebihan, yaitu pemanfaatan lahan akan lebih efisien dan dapat berfungsi sebagai penambah nilai estetika pekarangan salah satu permasalahan dalam budidaya skala rumah tangga adalah pemilihan media tumbuh tanaman yang tepat.

Media tumbuh merupakan tempat berkembangnya akar dan penyedia hara, air serta udara bagi tanaman. Menurut Agoes (1994), medium tumbuh yang baik harus memenuhi syarat sebagai berikut : tidak mudah padat, mampu menyediakan air dan unsur hara yang dibutuhkan tanaman, mempunyai aerase dan drainase yang baik, dapat mempertahankan kelembaban di sekitar perakaran, dan tidak menjadi sumber penyakit bagi tanaman. Upaya yang dapat dilakukan adalah dengan menggunakan pupuk organik. Penggunaan pupuk organik sebagai campuran medium tumbuh sangat menguntungkan, karena pupuk organik memiliki peran seperti yang dinyatakan oleh Hardjowigeno (1987) yakni memperbaiki struktur tanah, meningkatkan aktivitas mikroba tanah, meningkatkan kemampuan mengikat air, meningkatkan kapasitas tukar kation tanah sehingga kationkation hara yang penting tidak mudah mengalami pencucian dan tersedia bagi tanaman, dan meningkatkan kertersediaan unsur hara. Salah satu cara meningkatkan unsur hara bagi tanaman adalah dengan penambahan pupuk organik.

Pupuk organik yang banyak digunakan oleh petani diantaranya pupuk kandang dan kompos TKKS. Said (1996) menyatakan bahwa karakteristik dari kompos tandan kosong kelapa sawit (TKKS) antara lain merupakan butiran kasar dan homogen sehingga dapat mengurangi kerapatan isi tanah dan mengurangi resiko sebagai pembawa hama tanaman, pHnya normal (6-7) sehingga dapat membantu kelarutan unsur hara. Menurut Andayani dan Sarido (2013) pupuk kandang ayam memiliki tekstur dengan butiran halus yang mudah terdekomposisi sehingga unsur hara cepat tersedia bagi tanaman. Iwan (2002) melaporkan bahwa pupuk kandang sapi memiliki kandungan $\mathrm{K}$ lebih tinggi dibandingkan pupuk kandang lain. Pemberian pupuk kandang sapi dapat meningkatkan ketersediaan hara tanah dan mengurangi pengaruh buruk dari aluminium. Pupuk kandang kambing dengan kandungan $\mathrm{N}$ dan $\mathrm{K}$ yang cukup tinggi juga baik bagi tanaman. Menurut Widayati dan Widalestari (1996), kotoran kambing mengandung 40-50\% bahan kering dan sejumlah nitrogen yang sangat bermanfaat bagi tanah maupun tanaman. Kadar air pupuk kandang kambing relatif lebih rendah dari pupuk kandang sapi dan sedikit lebih tinggi dari pupuk kandang ayam.

Penelitian ini bertujuan untuk mengetahui pengaruh pemberian beberapa jenis pupuk organik sebagai campuran medium tumbuh terhadap pertumbuhan dan hasil baby kailan secara vertikultur.

\section{METODE PENELITIAN}

Penelitian dilaksanakan di Kebun Percobaan Fakultas Pertanian Universitas Riau Kampus Bina Widya KM 12,5 Kelurahan Simpang Baru, Kecamatan Bina Widya, Pekanbaru. Penelitian berlangsung selama empat bulan mulai dari bulan Februari sampai Mei 2019.

Bahan yang digunakan dalam penelitian ini adalah benih tanaman kailan varietas Nova, top soil, pupuk kandang sapi, pupuk kandang kambing, pupuk kandang ayam, kompos tandan kosong kelapa sawit, pasir, dan label. Alat yang digunakan dalam penelitian ini adalah cangkul, papan, polybag ukuran $20 \mathrm{~cm}$ x $15 \mathrm{~cm}$ dan ukuran $5 \mathrm{~cm}$ x $5 \mathrm{~cm}$, kayu, paku, palu, gergaji, meteran, parang, gembor, ayakan, polynet, tali raffia, timbangan digital, gelas ukur $5 \mathrm{ml}$, handsprayer, alat tulis, dan alat dokumentasi.

Penelitian ini dilaksanakan secara eksperimen yang terdiri dari empat perlakuan dan disusun menggunakan rancangan acak kelompok (RAK). Perlakuan tersebut yakni jenis pupuk $(\mathrm{P})$ organik yang terdiri dari: $\mathrm{P} 1$ : Pupuk kandang sapi; P2 : Pupuk kandang ayam; P3 : Pupuk kandang kambing; dan P4 : Kompos TKKS.

Setiap perlakuan diulang sebanyak lima kali sehingga diperoleh 20 unit percobaan dan masing-masing unit terdiri atas enam tanaman, sehingga total terdiri atas 120 tanaman. Seluruh tanaman tersebut diamati. Untuk melihat pengaruh dari perlakuan yang diberikan pada tanaman kailan maka data pengamatan yang diperoleh dianalisis menggunakan program Statistical Analysis System (SAS). Data hasil sidik ragam dilanjutkan dengan Uji BNT pada taraf 5\% menggunakan program $S A S$. 


\section{HASIL DAN PEMBAHASAN}

\section{Tinggi tanaman}

Hasil sidik ragam menunjukkan bahwa pemberian beberapa jenis pupuk organik berpengaruh nyata terhadap parameter tinggi tanaman kailan. Rerata tinggi tanaman baby kailan disajikan pada Tabel 1 .
Tabel 1 menunjukkan bahwa pada penanaman pertama perlakuan kompos TKKS menghasilkan tanaman baby kailan yang nyata lebih tinggi dibandingkan dengan pupuk kandang kambing, pupuk kandang ayam dan pupuk kandang sapi dengan tinggi tanaman baby kailan berturut-turut $19,71 \mathrm{~cm}, 16,38 \mathrm{~cm}$ dan $17,44 \mathrm{~cm}$.

Tabel 1. Rerata tinggi tanaman baby kailan $(\mathrm{cm})$ dengan pemberian beberapa jenis pupuk organik

\begin{tabular}{cc}
\hline Pupuk Organik & Rerata tinggi baby kalian $(\mathrm{cm})$ \\
\hline Kompos TKKS & $23,24 \mathrm{a}$ \\
PK kambing & $19,71 \mathrm{~b}$ \\
PK ayam & $16,38 \mathrm{c}$ \\
PK sapi & $17,44 \mathrm{c}$ \\
\hline Keterangan: - Angka - angka pada kolom yang sama diikuti huruf kecil yang sama menunjukan berbeda tidak nyata \\
menurut uji BNT pada taraf 5\%
\end{tabular}

\section{Jumlah daun}

Hasil sidik ragam menunjukkan bahwa pemberian beberapa jenis pupuk organik berpengaruh nyata terhadap parameter jumlah daun baby kailan. Rerata jumlah daun tanaman baby kailan disajikan pada Tabel 2.

Tabel 2. Rerata jumlah daun baby kailan (helai) dengan pemberian beberapa jenis pupuk organik.

\begin{tabular}{cc}
\hline Pupuk Organik & Rerata jumlah daun baby kalian $(\mathrm{cm})$ \\
\hline Kompos TKKS & $5,30 \mathrm{a}$ \\
PK kambing & $4,21 \mathrm{~b}$ \\
PK ayam & $3,65 \mathrm{bc}$ \\
PK sapi & $3,15 \mathrm{c}$ \\
\hline Keterangan: & - Angka - angka pada kolom yang sama diikuti huruf kecil yang sama menunjukan berbeda tidak nyata \\
menurut uji BNT pada taraf 5\% & \\
- PK (Pupuk kandang) &
\end{tabular}

Tabel 2 menunjukkan bahwa perlakuan kompos TKKS menghasilkan jumlah daun terbanyak dibandingkan dengan perlakuan pupuk organik lainnya. Perlakuan kompos menghasilkan jumlah daun terbanyak adalah 5,30 helai dan berbeda nyata dengan pupuk kandang kambing, pupuk kandang ayam dan pupuk kandang sapi dengan jumlah daun baby kailan berturut-turut 4,21 helai, 3,65 helai dan 3,15 helai.

\section{Berat segar tanaman.}

Hasil sidik ragam menunjukkan bahwa pemberian beberapa jenis pupuk organik berpengaruh nyata terhadap parameter berat segar tanaman baby kailan. Rerata berat segar tanaman baby kailan disajikan pada Tabel 3.

Tabel 3. Rerata berat segar tanaman baby kailan (g) dengan pemberian beberapa jenis pupuk organik

\begin{tabular}{cc}
\hline Pupuk Organik & Rerata berat segar baby kailan $(\mathrm{g})$ \\
\hline Kompos TKKS & $26,02 \mathrm{a}$ \\
PK kambing & $15,86 \mathrm{~b}$ \\
PK ayam & $10,91 \mathrm{~b}$ \\
PK sapi & $10,39 \mathrm{~b}$ \\
\hline Keterangan: & Angka - angka pada kolom yang sama diikuti huruf kecil yang sama menunjukan berbeda tidak nyata \\
menurut uji BNT pada taraf 5\% & \\
- PK (Pupuk kandang)
\end{tabular}

Tabel 3 menunjukkan bahwa perlakuan kompos TKKS menghasilkan berat segar tertinggi dan berbeda nyata dengan perlakuan lainnya. Berat segar tanaman baby kailan yang ditanam secara vertikultur menunjukkan bahwa perlakuan kompos menghasilkan berat segar 
tanaman terbanyak yakni $26,02 \mathrm{~g}$, berbeda nyata dengan perlakuan lainnya.

\section{Berat layak konsumsi per tanaman}

Hasil sidik ragam menunjukkan bahwa pemberian beberapa jenis pupuk organik berpengaruh nyata terhadap parameter berat layak konsumsi per tanaman pada baby kailan. Rerata berat layak konsumsi per tanaman pada baby kailan disajikan pada Tabel 4.

Tabel 4. Rerata berat layak konsumsi tanaman baby kailan (g) dengan pemberian beberapa jenis pupuk organik.

\begin{tabular}{cc}
\hline Pupuk Organik & Rerata berat layak konsumsi baby kailan $(\mathrm{g})$ \\
\hline Kompos TKKS & $23,80 \mathrm{a}$ \\
PK kambing & $14,42 \mathrm{~b}$ \\
PK ayam & $9,62 \mathrm{~b}$ \\
PK sapi & $8,79 \mathrm{~b}$ \\
\hline
\end{tabular}

Keterangan: - Angka - angka pada kolom yang sama diikuti huruf kecil yang sama menunjukan berbeda tidak nyata menurut uji BNT pada taraf 5\%

- PK (Pupuk kandang)

Tabel 4 menunjukkan bahwa pada penanaman pertama perlakuan kompos TKKS menghasilkan berat layak konsumsi per tanaman tertinggi dan berbeda nyata dengan perlakuan lainnya. Perlakuan kompos TKKS menghasilkan berat segar tanaman terbanyak yakni 23,80 g, berbeda nyata dengan pupuk kandang kambing, pupuk kandang ayam dan pupuk kandang sapi dengan berat layak konsumsi per tanaman baby kailan berturutturut $14,42 \mathrm{~g}, 9,62 \mathrm{~g}$ dan $8,79 \mathrm{~g}$.

\section{Volume akar}

Hasil sidik ragam menunjukkan bahwa pemberian beberapa jenis pupuk organik berpengaruh nyata terhadap parameter volume akar tanaman baby kailan. Rerata volume akar tanaman baby kailan dapat dilihat pada Tabel 5 .

Tabel 5. Rerata volume akar tanaman baby kailan (ml) dengan pemberian beberapa jenis pupuk organik.

\begin{tabular}{cc}
\hline Pupuk Organik & Rerata volume akar baby kailan $(\mathrm{ml})$ \\
\hline Kompos TKKS & $0,77 \mathrm{a}$ \\
PK kambing & $0,50 \mathrm{~b}$ \\
PK ayam & $0,35 \mathrm{~b}$ \\
PK sapi & $0,46 \mathrm{~b}$ \\
\hline
\end{tabular}

Keterangan: - Angka - angka pada kolom yang sama diikuti huruf kecil yang sama menunjukan berbeda tidak nyata menurut uji BNT pada taraf 5\%

- PK (Pupuk kandang)

Tabel 5 menunjukkan pada penanaman pertama perlakuan kompos TKKS menghasilkan volume akar tertinggi dan berbeda nyata dengan perlakuan lainnya.

Hasil penelitian penggunaan beberapa jenis pupuk organik terhadap pertumbuhan dan hasil tanaman baby kailan yang ditanam secara vertikuktur memperlihatkan respon yang berbeda-beda. Pemberian kompos TKKS cenderung lebih baik dalam meningkatkan tinggi tanaman (Tabel 1), jumlah daun (Tabel 2), berat segar tanaman (Tabel 3), berat layak konsumsi (Tabel 4) dan volume akar (Tabel 5) dibandingkan perlakuan lainnya.

Perlakuan kompos TKKS nyata meningkatkan tinggi tanaman, jumlah daun, berat segar tanaman, berat layak konsumsi dan volume akar pada penanaman pertama dibandingkan perlakuan lainnya dikarenakan tekstur kompos TKKS berupa butiran kasar dan homogen sehingga dapat mengurangi kerapatan isi tanah dan meningkatkan pori tanah. Bahan organik yang terkandung di dalam kompos TKKS juga dapat meningkatkan kapasitas medium tumbuh untuk memegang air sehingga menjadikan medium tumbuh menjadi lebih baik. Hal ini juga meningkatkan perkembangan akar yang dibuktikan dengan volume akar yang lebih besar (Tabel 5) sehingga kapasitas akar dalam penyerapan air dan unsur hara lebih baik dibanding perlakuan lainnya. Hara dan air yang diserap tanaman melalui akar akan dimanfaatkan untuk proses metabolisme yang 
hasilnya dimanfaatkan untuk pertumbuhan dan perkembangan baby kailan.

Pemberian kompos TKKS sebagai sumber bahan organik menyebabkan tanah menjadi lebih gembur dibanding perlakuan lainnya karena bahan organik dapat menurunkan berat isi tanah. Tanah yang gembur akan meningkatkan pori tanah yang nantinya akan menyebabkan akar tanaman mudah tumbuh dan berkembang. Tanah yang gembur mengidentifikasikan bahwa berat isi mengalami penurunan dan pori tanah mengalami peningkatan. Buckman dan Brady (1982) menyatakan bahwa pemberian bahan organik menyebabkan agregat tanah menjadi stabil yang nantinya tanah menjadi gembur. Hasil ini sejalan dengan hasil penelitian Muyassir et al. (2012) yang melaporkan bahwa penambahan bahan organik dapat menurunkan berat isi tanah, menaikan stabilitas agregat tanah dan meningkatkan porositas pada tanah.

Pemberian kompos TKKS sebagai campuran medium tumbuh dapat meningkatkan ketersediaan unsur hara karena kandungan nutrisi yang lebih tinggi dibanding perlakuan sehingga proses metabolisme tanaman yakni fotosintesis maupun respirasi berjalan dengan baik dan fotosintat yang dihasilkan juga lebih banyak. Fotosintat ditranslokasikan ke seluruh organ tanaman. Fotosintat dan energi kemudian dimanfaatkan untuk pertumbuhan dan perkembangan tanaman baby kailan.

Penambahan kompos TKKS yang mengandung unsur hara tinggi membantu mempertahankan jalannya proses fotosintesis dengan baik yang pada akhirnya pertumbuhan dan hasil tanaman yang didapat menjadi lebih baik. Hal ini seperti yang dinyatakan Lakitan (2000) bahwa pada proses fotosintesis, tanaman memerlukan unsur hara esensial dalam jumlah yang cukup yang diserap tanaman melalui akar. Fotosintat yang dihasilkan kemudian ditranslokasikan ke organ atau jaringan tanaman lain agar dapat dimanfaakan untuk pertumbuhan atau disimpan sebagai cadangan makanan (karbohirat). Menurut Sarief (1985) ketersediaan unsur hara yang baik untuk diserap tanaman juga mempengaruhi pertumbuhan tanaman dalam pembesaran sel.

Hasil akhir dari pertumbuhan dan perkembangan sel tanaman dapat dilihat berdasarkan berat segar tanaman dan berat layak konsumsi. Berat segar tanaman kailan berkaitan dengan berat layak konsumsi kailan karena berat layak konsumsi merupakan berat segar yang dapat dikonsumsi tanpa menyertakan akar dan daun yang rusak. Besarnya hasil yang diperoleh dari berat tanaman yang dikonsumsi disebabkan oleh tinggi tanaman yang lebih tinggi dan jumlah daun yang lebih banyak dan perlakuan kompos TKKS menunjukkan hasil lebih baik dibandingkan dengan perlakuan lainnya.

Menurut Mangoensoekarjo dan Semangun, (2005) TKKS berpotensi dimanfaatkan sebagai pupuk organik karena mengandung unsur hara yang dibutuhkan oleh tanaman baik itu mikro maupun makro. Kandungan nutrisi kompos tandan kosong kelapa sawit yaitu: C 35\%, N 2,34\%, C/N 15, P 0,31\%, K 5,53\%, Ca 1,46\%, Mg 0,96\%, dan Air 52\%.

\section{KESIMPULAN}

Berdasarkan hasil penelitian yang telah dilakukan dapat disimpulkan bahwa Pemberian kompos TKKS nyata lebih baik dalam meningkatkan tinggi tanaman $23,24 \mathrm{~cm}$, jumlah daun 5,30 helai, berat segar tanaman $26,02 \mathrm{~g}$, berat layak konsumsi 23,80 g dan volume akar $0,77 \mathrm{ml}$ dibandingkan perlakuan lainnya.

\section{UCAPAN TERIMA KASIH}

Kepada Kepada PLP UPT Kebun Percobaan Fakultas Pertanian Universitas Riau Kampus Bina Widya km12,5 Pekanbaru, yang telah membantu kelancaran pelaksanaan penelitian ini.

\section{DAFTAR PUSTAKA}

Agoes, D. 1994. Berbagai Jenis Media Tanam dan Penggunaannya. Penebar Swadaya. Jakarta.

Andayani dan L. Sarido. 2013. Uji empat jenis pupuk kandang terhadap pertumbuhan dan hasil tanaman cabai keriting (Capsicum annum L.). Jurnal Agrifor. 9(1): 22-29.

Buckman, H.O. dan Brady, N.C. 1982. Ilmu Tanah. Bhratara Karya Aksara. Jakarta.

Hardjowigeno, S. 1987. Ilmu Tanah. Mediyatama Sarana Perkasa. Jakarta.

Hendra, H. A dan A. Andoko. 2014. Bertanam Sayuran Hidroponik Ala Paktani Hidrofram. Agromedia. Jakarta. 
Iwan. 2002. Pupuk Kotoran Sapi. Http://balittanah.litbang.deptan.go.id/do kumentasi/buku/pupuk/ pupuk4. pdf. Diakses tanggal 20 November 2018.

Mangoensoekarjo, S. dan H. Semangun. 2005. Manajemen Agribisnis Kelapa Sawit. Gadjah Mada University Press. Yogyakarta.

Muyassir, Sufardi, dan Saputra, I. 2012. Perubahan sifat fisika Inceptisol akibat perbedaan jenis dan dosis pupuk organik. Lentera 12 (1): 1-8.

Pracaya. 2005. Kol alias Kubis. Penebar Swadaya. Jakarta.
Said, E. G. 1996. Penanganan dan Pemanfaatan Limbah Kelapa Sawit. Trubus Agriwidya. Bogor.

Samadi, B. 2013. Budidaya Intensif Kailan secara Organik dan Anorganik. Pustaka Mina. Jakarta.

Sanusi dan Benny. 2010. Sukses Bertanam Sayuran di Lahan Sempit. PT Agromedia Pustaka. Jakarta.

Sarief, E. S. 1985. Kesuburan dan Pemupukan Tanah Pertanian. Pustaka Buana. Bandung.

Widayati, E. dan Y. Widalestari. 1996. Limbah untuk Pakan Ternak. Trubus Agrisarana. Surabaya. 